\title{
Vitamin D in adult health and disease: a review and guideline statement from Osteoporosis Canada (summary)
}

\author{
David A. Hanley MD, Ann Cranney MB BCh, Glenville Jones PhD, Susan J. Whiting PhD, \\ William D. Leslie MD; for the Guidelines Committee of the Scientific Advisory Council \\ of Osteoporosis Canada
}

Previously published at www.cmaj.ca

See also the complete guideline article by Hanley and colleagues at www.cmaj.ca

$\mathrm{T}$ he 2002 guidelines for the management of osteoporosis published by Osteoporosis Canada ${ }^{1}$ identified adequate vitamin D status, in addition to calcium from diet or supplements, as essential for the prevention of osteoporosis. Since then, our knowledge of the role of vitamin $\mathrm{D}$ (both $\mathrm{D}_{2}$ and $\mathrm{D}_{3}$ ) in fractures, falls and other health outcomes has expanded. Canadian recommendations for vitamin $\mathrm{D}$, which are more than 10 years old, have never been supported by adequately conducted dose-finding studies ${ }^{2}$ and were derived primarily from early nutritional science estimates of the minimal intake necessary to prevent extreme deficiency states.

We reviewed advances in knowledge about vitamin D physiology and optimal intake requirements for adults (except in pregnancy and during lactation) to update the 2002 clinical practice guidelines. In reviewing trials of vitamin $\mathrm{D}$, it is important to remember that, unlike the situation for trials of pharmacologic agents, any reported benefits of vitamin D supplementation reflect correction of a deficiency in the population under study.

\section{Methods}

We systematically searched the MEDLINE database, for the period 1996 to June 30, 2008, and the Cochrane Library using the terms "vitamin D," "vitamin D deficiency," "25hydroxyvitamin D," "meta-analysis" and "systematic review." We identified 168 potentially relevant papers. After removal of duplicates and screening of the abstracts by two reviewers (including A.C.), 16 relevant systematic reviews remained. We included systematic reviews of randomized controlled trials and observational studies that assessed the following outcomes: fractures, falls, death or extraskeletal outcomes. We used the Assessment of Multiple Systematic Reviews instrument ${ }^{3}$ to evaluate the methodologic quality of reviews published after the cutoff date for literature reviewed in the 2002 guideline $^{1}$ until June 30, 2008 (see Appendices 1 and 2 of the full guideline ${ }^{4}$ available at www.cmaj.ca/cgi/content/full /cmaj.080663/DCI). For levels of evidence and grading of the recommendations, we followed the system used in the 2002 guidelines. ${ }^{1}$ A multidisciplinary expert panel, including the authors of this article, reviewed the identified articles. As detailed in Table 1 of the full guideline, ${ }^{4}$ we assigned a level of

\section{Key points}

- Vitamin $D$ is essential for the prevention of osteoporosis.

- A serum level of 25-hydroxyvitamin D above $75 \mathrm{nmol} / \mathrm{L}$ reflects optimal vitamin $D$ intake or synthesis to consistently improve clinical outcomes such as fracture risk; vitamin D supplementation is needed to achieve this target.

- Recommended intake for low-risk and younger adults should be increased to $10-25 \mu \mathrm{g}(400-1000 \mathrm{IU})$ daily and for high-risk and older adults, to $20-50 \mu \mathrm{g}(800-2000 \mathrm{IU})$ daily, with consideration of higher doses (key change from 2002 guideline)

- For individuals being treated with pharmacologic agents for osteoporosis, vitamin D status should be assessed by serum measurement of 25-hydroxyvitamin D after three months of vitamin D supplementation (key change from 2002 guideline).

evidence to each summary point (from $1=$ highest to $4=$ lowest), and a grade to each recommendation, according to a system that incorporated both level of evidence and expert consensus (from $\mathrm{A}=$ highest to $\mathrm{D}=$ lowest). The Guidelines Committee and the Executive Committee of Osteoporosis Canada's Scientific Advisory Council approved the recommendations.

\section{Assessment of vitamin D}

\section{Measurement and assay}

After synthesis in the skin or ingestion through the diet, vita$\min \mathrm{D}_{3}$ is stored in the liver, adipose tissue and muscle, where it has a half-life of about 60 days. It is converted into 25hydroxyvitamin $\mathrm{D}_{3}$ in the hepatocytes..$^{5-7}$ The serum concentration of 25-hydroxyvitamin $\mathrm{D}_{3}$ is the best indicator of the

From the Departments of Medicine, Oncology and Community Health Sciences (Hanley), University of Calgary, Calgary, Alta.; the Department of Medicine (Cranney), University of Ottawa, Ottawa, Ont.; the Department of Biochemistry (Jones), Queen's University, Kingston, Ont.; College of Pharmacy and Nutrition (Whiting), University of Saskatchewan, Saskatoon, Sask.; and the Departments of Radiology, Nuclear Medicine and Medicine (Leslie) University of Manitoba, Winnipeg, Man. Members of the Guidelines Committee of the Scientific Advisory Council of Osteoporosis Canada are listed in the Acknowledgements section of this article.

CMAJ 2010. DOI:10.1503/cmaj.091062 
nutritional and functional status of vitamin D. ${ }^{2}$ It is imperative that clinical laboratories measuring 25-hydroxyvitamin $\mathrm{D}_{3}$ participate in external proficiency testing. ${ }^{8-10}$ Although circulating calcitriol $\left(1 \alpha, 25\right.$-dihydroxyvitamin $\mathrm{D}_{3}$ or 1,25 dihydroxycholecalciferol) is the vitamin $\mathrm{D}$ hormone regulating intestinal calcium and phosphate absorption, it is not an appropriate indicator of clinical vitamin D status in most cases. ${ }^{5}$ The classification of vitamin D status is outlined in Table 1. Vitamin $\mathrm{D}_{2}$ (ergocalciferol) follows the same metabolic pathways as vitamin $\mathrm{D}_{3}$ but may have lesser activity.

\section{Monitoring of serum 25-hydroxyvitamin D}

For most Canadians, the recommendations for vitamin D supplementation outlined here should result in adequate blood levels, with no need for routine testing for vitamin D deficiency. However, in cases where deficiency is suspected (e.g., intestinal malabsorption states such as celiac disease) or where deficiency could affect the person's response to other types of therapy (e.g., in osteoporosis requiring pharmacologic therapy), vitamin $\mathrm{D}$ deficiency should be ruled out by measurement of serum 25-hydroxyvitamin D.

The half-life of 25-hydroxyvitamin D in the body is 15-20 days. ${ }^{6}$ With standard-dose supplementation, serum 25 hydroxyvitamin D plateaus after three to four months. ${ }^{11}$ Therefore, to monitor a patient's response, serum 25-hydroxyvitamin D should be measured no sooner than three months after treatment begins. After administration of high-dose oral or parenteral vitamin D replacement (e.g., $500000 \mathrm{IU})$, the peak 25-hydroxyvitamin D level may be achieved in one month. ${ }^{12}$

\section{Factors associated with vitamin D deficiency}

Many factors and conditions are associated with vitamin D deficiency. Some of these are causative (e.g., marked avoidance of ultraviolet radiation or malabsorption) and others are simply associated with decreased exposure to sunlight and poor nutrition (e.g., chronic illness or renal failure). ${ }^{13,14}$

\section{Sources of vitamin D}

\section{Exposure to the sun}

The skin synthesizes vitamin $\mathrm{D}_{3}$ from 7-dehydrocholesterol in response to ultraviolet $\mathrm{B}$ radiation in sunlight. ${ }^{15}$ This synthetic

\begin{tabular}{|c|c|c|}
\hline $\begin{array}{l}\text { Serum } 25-\mathrm{OH}-\mathrm{D}, \\
\mathrm{nmol} / \mathrm{L} \dagger \neq\end{array}$ & Category & $\begin{array}{l}\text { Level of } \\
\text { evidence }\end{array}$ \\
\hline$<25$ & Vitamin D deficiency & 3 \\
\hline $25-75$ & Vitamin D insufficiency§ & 2 \\
\hline$>75$ & Desirable vitamin D status & 3 \\
\hline$>250$ & Potential adverse effects & 2 \\
\hline
\end{tabular}

*Reproduced, with permission, from Hanley et al. ${ }^{4}$

†Assumes that serum 25-OH-D is measured by a clinical laboratory

participating in an external quality assurance program.

$\ddagger 2.5 \mathrm{nmol} / \mathrm{L}=1 \mathrm{ng} / \mathrm{mL}$.

$\S$ "Insufficiency" is a milder form of deficiency and should preferably be termed "suboptimal vitamin D status." process depends on many factors, including latitude, altitude, time of year and day, weather, age, skin pigmentation type, clothing, activity and other aspects of the environment. Production of vitamin $\mathrm{D}$ in the skin falls to near zero for four to five months of the year in Canada, which raises the risk for vitamin D insufficiency or deficiency. ${ }^{16-19}$

\section{Food sources}

The influence of the diet on vitamin D status is minimal, given the typical daily intake of 3.7-5.9 $\mu \mathrm{g}$ or $148-236 \mathrm{IU},{ }^{20}$ but it may be enough to prevent severe deficiency states, such as rickets. The few foods that naturally contain vitamin D (e.g., certain fish) are not consumed regularly. Consequently, Canadians depend on fortified dietary sources or supplements to maintain adequate vitamin D status.

\section{Supplements}

Serum 25-hydroxyvitamin D increases by $0.7-2.0 \mathrm{nmol} / \mathrm{L}$ for each $1 \mu \mathrm{g}$ (40 IU) of vitamin $\mathrm{D}_{3}$ ingested daily. ${ }^{11,21}$ For optimal vitamin $\mathrm{D}$ status, adult Canadians probably require vitamin $\mathrm{D}$ supplementation of 20-50 $\mu \mathrm{g}$ (800-2000 IU) daily. Doses over $50 \mu \mathrm{g}$ (2000 IU) can be safely administered under medical supervision. ${ }^{2}$ Treatment of severe deficiency (rickets or osteomalacia) requires higher doses, e.g., $1250 \mu \mathrm{g}$ (50 000 IU) daily for two to four weeks, then weekly or biweekly, with monitoring of serum 25-hydroxyvitamin $\mathrm{D}$ at one and three months. These dosages are based on an assumption that the patient can absorb an orally administered dose. ${ }^{5}$

\section{Safety and toxicity of vitamin D supplementation}

Excessive use of vitamin D supplements has the potential to cause progressive accumulation and toxic effects, presenting as hypercalcemia and renal damage. Canada's "tolerable upper intake level" (the highest level of daily nutrient intake presenting no risk of adverse effects) is $50 \mu \mathrm{g}$ (2000 IU) vitamin D for adults. ${ }^{2}$ By definition, there is no need to monitor patients' serum calcium or renal function unless doses above the tolerable upper level are administered. However, this level is undoubtedly too conservative and may eventually be revised upward, since toxic effects occur only with prolonged (at least several months) daily intake of more than $1000 \mu \mathrm{g}(40000 \mathrm{IU}) .{ }^{6,22}$

\section{Traditional roles of vitamin D}

\section{Effect on bone mineral density}

Low bone mineral density is a risk factor for osteoporotic fracture, and vitamin D deficiency is associated with low bone mineral density. ${ }^{1}$ Observational studies have shown an association between higher serum 25-hydroxyvitamin D (range 40-90 nmol/L) and higher bone mineral density. ${ }^{23-25}$ Randomized controlled trials have shown that vitamin D supplements significantly increase bone mineral density. ${ }^{26-28}$

\section{Effect on fractures}

Observational studies have shown an association between low 25-hydroxyvitamin D and fractures. Clinical trials of vitamin $\mathrm{D}$ supplementation have been plagued by methodological issues: lack of determination of optimal dose, poor adherence, 
inadequate assessment of vitamin D status before or after supplementation and concurrent intervention with other osteoporosis therapies. However, it appears that $20 \mu \mathrm{g}$ (800 IU) vitamin $\mathrm{D}_{3}$ given daily in combination with calcium reduces the risk of hip and nonvertebral fractures, especially for elderly patients living in institutions. ${ }^{28-33}$

\section{Effect on falls}

Vitamin D may improve muscle strength and lower-extremity function, but the results of studies of fall prevention are inconsistent, because of differences in populations, doses and methods of capturing data on falls..$^{31,34-37}$ One meta-analysis suggested that vitamin $\mathrm{D}_{3}$ at a daily dose of $20 \mu \mathrm{g}$ (800 IU) reduced the risk of falling, particularly in trials that adequately documented the ascertainment of falls..$^{38}$

\section{Nontraditional roles of vitamin D}

Calcitriol is produced locally from circulating 25-hydroxyvitamin D in many tissues (e.g., skin, colon, prostate, breast, pancreas, heart and immune system), a process that is not regulated by serum calcium, phosphate or parathyroid hormone. ${ }^{5}$ Many important physiologic actions of vitamin D outside the musculoskeletal system are now being explored. For example, vitamin D may have important antiproliferative and prodifferentiation properties. ${ }^{5,39}$ Observational studies have shown a relationship between sufficient vitamin D status and lower risk of cancers..$^{40-42}$

Vitamin D may lower blood pressure by downregulating the production of renin. It may also stimulate the production and secretion of insulin and modulate immune function. ${ }^{5}$ In epidemiologic studies, low circulating levels of vitamin $\mathrm{D}$ were associated with increased risk of multiple sclerosis. ${ }^{43}$ Vitamin Ddependent processes affect macrophage lysis of Mycobacterium tuberculosis ${ }^{44}$ Epidemiologic studies have linked vitamin D deficiency in early life with later onset of diabetes mellitus. ${ }^{45}$

The nontraditional actions of vitamin D have not been investigated to the same extent as its effects on mineral metabolism. There has been a paucity of intervention studies to test hypothesized benefits, and none of the studies to date used sufficient doses of vitamin $\mathrm{D}$ or were adequately powered. Systematic reviews or meta-analyses of the available literature are therefore unlikely to provide answers in this area. A prime example is the recently released, exhaustive report of the Agency for Healthcare Research and Quality, ${ }^{33}$ a systematic review of the evidence for vitamin D affecting health outcomes. This review found little or weak evidence supporting the nontraditional actions of vitamin D and could make no recommendations other than that more research is needed.

Summary statements about assessment of vitamin D levels, the safety of supplementation and the roles of vitamin $\mathrm{D}$ are presented in Box 1 .

\section{Approach to supplementation}

Recommendations for vitamin D supplementation are outlined in Box 2. Given the limitations in our knowledge of optimal intake levels, evidence of the safety and potential benefits of vitamin D supplementation support recommendations aiming for serum 25-hydroxyvitamin D levels above 75 $\mathrm{nmol} / \mathrm{L}$. For most Canadian adults, exposure to sunlight and dietary intake are insufficient to maintain this level through-

\section{Box 1: Summary statements on vitamin D*}

\section{Assessment of vitamin D}

1. Measurement of 25-hydroxyvitamin $D$ in the serum (with no restrictions on the timing of collection ) is the best indicator of vitamin D sufficiency ${ }^{2}$ (level 2 evidence).

2. In the absence of external laboratory proficiency testing, serum 25-hydroxyvitamin D values from different clinical laboratories cannot be assumed to be comparable ${ }^{8,10}$ (level 2 evidence).

3. Monitoring of routine vitamin $\mathrm{D}$ supplementation by measurement of serum 25-hydroxyvitamin $D$ is unnecessary (level 4 evidence). Monitoring of high-risk patients and those with osteoporosis should not be performed before three months of standard supplementation (20-50 $\mu \mathrm{g}$ [800-2000 IU daily) $)^{11}$ (level 2 evidence). Patients taking daily doses above Health Canada's "tolerable upper intake level" (currently set at $50 \mu \mathrm{g}$ [2000 IU]) should undergo monitoring of serum 25hydroxyvitamin D (level 4 evidence).

\section{Sources of vitamin D}

1. In Canada, some vitamin $D$ is obtained with safe exposure to the sun during the summer months ${ }^{46-48}$ (level 1 evidence), but exposure to sunlight and dietary intake are insufficient to maintain average serum 25-hydroxyvitamin D concentration above $75 \mathrm{nmol} / \mathrm{L}$ throughout the year ${ }^{11,18,19}$ (level 2 evidence).

2. A daily intake of $25 \mu \mathrm{g}$ vitamin $D_{3}$ (1000 IU) - a safe, commonly available dose - will raise the average serum level of 25 -hydroxyvitamin D by $15-25 \mathrm{nmol} / \mathrm{L}^{11,21}$ (level 2 evidence).

3. The upper level for safe vitamin $D_{3}$ intake has not been well defined but is probably as high as $250 \mu \mathrm{g}$ (10 $000 \mathrm{IU})$ daily $\mathrm{y}^{11,22}$ (level 2 evidence). In clinical practice, supplementation with this dose of vitamin $D$ is rarely required (level 4 evidence).

\section{Effect of supplementation on bone mineral density,}

\section{fractures and falls}

1. Supplementation with vitamin $D_{3}$ and calcium increases bone density in postmenopausal women and in men over age 50 years $^{24,27,28,49}$ (level 1 evidence).

2. Vitamin $D_{3}$ at daily doses of $20 \mu \mathrm{g}$ (800 IU), in combination with calcium (1000 $\mathrm{mg})$, reduces the risk of hip and nonvertebral fractures in elderly people living in institutions (level 1 evidence). The evidence for community-dwelling individuals is less strong ${ }^{50}$ (level 2 evidence).

3. There is evidence that supplementation with $20 \mu \mathrm{g}$ (800 IU) vitamin $D_{3}$ daily reduces the risk of falls, particularly from trials with adequate ascertainment of falls ${ }^{38}$ (level 2 evidence).

\section{Nontraditional roles of vitamin D}

1. Vitamin $D$ insufficiency has been associated with malignancies ${ }^{40}$ (especially colorectal cancer $^{41}$ ), diabetes mellitus, ${ }^{45}$ multiple sclerosis ${ }^{51}$ and impaired immune response $^{44}$ (level 3 evidence).

2. The benefits of vitamin $D$ for these nontraditional roles are associated with 25-hydroxyvitamin D levels above $75 \mathrm{nmol} / \mathrm{L}^{21,40}$ (level 3 evidence).

*Levels of evidence are explained in detail in the full guideline. ${ }^{4}$ In brief, levels of evidence range from very high quality (level $1+$, systematic overview or meta-analysis of randomized controlled trials) to very low quality (level 6, case series without controls). 
out the year, and vitamin D supplementation is therefore indicated. ${ }^{17-19}$ The clinical approach can take into account three "settings," which are based on suspicion for vitamin D insufficiency and its complications. The three settings are low risk for vitamin D deficiency, moderate risk for deficiency and receipt of pharmacologic therapy for osteoporosis.

Vitamin $D_{3}$ is the preferred supplementary form for humans, with vitamin $\mathrm{D}_{2}$ being available for large-dose prepa-

\section{Box 2: Recommendations for vitamin D supplementation*}

1. Adequate vitamin $D$ status, in addition to calcium from diet or supplements, is essential for the prevention of osteoporosis (level 1 evidence, grade A recommendation).

2. Administration of vitamin $D$ and calcium should not be used as the sole treatment for osteoporosis (level 1 evidence, grade A recommendation).

3. The optimal level of serum 25-hydroxyvitamin $D$ for musculoskeletal benefits is at least $75 \mathrm{nmol} / \mathrm{L}$ (level 2 evidence, grade B recommendation).

4. Laboratories performing 25-hydroxyvitamin D testing should take part in external proficiency surveys and should demonstrate that values reported for shared samples approximate the consensus values reported by others (level 4 evidence, grade $\mathrm{D}$ recommendation).

5. In healthy adults at low risk for vitamin $D$ deficiency (i.e., under age 50, without osteoporosis or conditions affecting vitamin $\mathrm{D}$ absorption or action), routine vitamin $\mathrm{D}$ supplementation (10-25 $\mu \mathrm{g}$ [400-1000 IU] daily) is recommended. Serum 25 -hydroxyvitamin $D$ should not be measured (level 5 evidence, grade $D$ recommendation).

6. Adults over 50 years of age are at moderate risk for vitamin $D$ deficiency. Supplementation with at least 20-25 $\mu \mathrm{g}$ (800-1000 IU) of vitamin $D_{3}$ daily is recommended. To achieve optimal vitamin $D$ status ( $>75 \mathrm{nmol} / \mathrm{L}$ ), many individuals may require supplementation at greater than $25 \mu \mathrm{g}$ (1000 IU) daily. Doses up to $50 \mu \mathrm{g}(2000 \mathrm{IU})$ are safe and do not require monitoring (level 3 evidence, grade $C$ recommendation).

7. For individuals receiving pharmacologic therapy for osteoporosis, measurement of serum 25-hydroxyvitamin D should follow three to four months of adequate supplementation and should not be repeated if the optimal level is achieved (grade $D$ recommendation).

8. Measurement of serum 25-hydroxyvitamin $D$ is recommended for individuals with recurrent fractures, bone loss despite osteoporosis treatment or comorbid conditions that affect vitamin $\mathrm{D}$ absorption or action (grade $\mathrm{D}$ recommendation). Dose requirements above Health Canada's current tolerable upper intake level $(50 \mu \mathrm{g}$ [2000 IU]) may be needed, in which case monitoring of serum 25 -hydroxyvitamin $D$ levels is required (level 4 evidence, grade $D$ recommendation).

9. Exposure to natural sunlight, when used in moderation (avoiding sunburn) and individualized to the person's skin type, can contribute to summertime vitamin D sufficiency (level 2 evidence, grade B recommendation).

10. Research is needed to better define the minimum required daily dose and the optimal dose for musculoskeletal and other health benefits, and to better establish the tolerable upper level for vitamin D supplementation (grade D recommendation).

* Levels of evidence and grades of recommendations are explained in detail in the full guideline. ${ }^{4}$ In brief, grades of recommendations range from $A$ (having level 1 or $1+$ evidence plus consensus) to D (having level 4,5 or 6 evidence and supported by consensus). rations. Calcitriol and its analogues are prescription products with narrow margins of safety and are not advised for the prevention or treatment of osteoporosis. For most adults, a vitamin $\mathrm{D}_{3}$ supplement at an initial daily dose of at least $20 \mu \mathrm{g}$ (800 IU) is appropriate. This dose is unlikely to raise the average serum 25-hydroxyvitamin D level by more than 20 nmol/L. ${ }^{11,21}$ To achieve desirable vitamin D status (> 75 $\mathrm{nmol} / \mathrm{L})$, many individuals will require higher doses.

Because vitamin D is stored in body tissues, a larger, less frequent dose may be preferred by some patients. A weekly dose of $250 \mu \mathrm{g}(10000 \mathrm{IU})$ vitamin $\mathrm{D}_{3}$ is available by prescription in some provinces. Some practitioners prescribe vitamin $\mathrm{D}_{2}$ at a dose of $1250 \mu \mathrm{g}(50000 \mathrm{IU})$ monthly.

\section{Knowledge gaps}

There is need for research to better define the minimum required dose and optimal daily dose for musculoskeletal and other health benefits, as well as the tolerable upper intake level for vitamin D. There is also a need for randomized controlled trials to clarify the benefits and risks (if any) of vitamin D supplementation at that optimal dose. The purported benefits of vitamin D beyond musculoskeletal disorders should be confirmed in clinical trials.

This article has been peer reviewed.

Competing interests: All authors were members of the Vitamin D Working Group of Osteoporosis Canada. David A. Hanley has been an investigator in clinical trials, participated in advisory boards or received speaking honoraria from the following companies: Amgen, Merck Frosst Canada, Proctor and Gamble Canada (now Warner-Chilcott), sanofi-aventis, Novartis, NPS Pharmaceuticals, Eli Lilly Canada, Pfizer, Wyeth-Ayerst, Roche, Servier, Abbott Laboratories and Nycomed. Glenville Jones serves on the scientific advisory board of the not-for-profit Vitamin D External Quality Assessment Scheme. $\mathrm{He}$ is also on the advisory board and has received a research grant from Cytochroma Inc. and is a member of the Genzyme speakers' bureau. Susan J. Whiting is a member of the International Institute for Nutrition and Bone Health, an educational initiative sponsored by Yoplait. She has received current or recent funding in the form of grants and contracts from the Canadian Institutes of Health Research and the Canadian Foundation for Dietetic Research. She is a nutrition consultant to Osteoporosis Canada. She has presented talks with sponsorship from the Dairy Farmers of Canada, the International Alliance of Dietary/Food Supplement Associations, the Vitamin D Society, GlaxoSmithKline and Amway/Nutrilite. William D. Leslie has received speaker fees and unrestricted research grants from Merck Frosst Canada Ltd; unrestricted research grants from sanofi-aventis, Procter and Gamble Pharmaceuticals Canada, Novartis, Amgen Pharmaceuticals Canada and Genzyme Canada; and has served on advisory boards for Genzyme Canada, Novartis and Amgen Pharmaceuticals Canada. None declared for Ann Cranney.

Contributors: All authors, as well as the other members of the Vitamin D Working Group (listed in the Acknowledgments section), participated in the conception and design of the vitamin D guideline project. David A. Hanley oversaw the writing project, recruited committee members, and edited and revised all section submissions. Ann Cranney wrote the Methods section and the section entitled "Traditional roles of vitamin D" and was one of the reviewers of the abstracts identified in the literature search. Glenville Jones wrote the section entitled "Assessment of vitamin D," Susan J. Whiting wrote the section entitled "Sources of vitamin D" and William D. Leslie wrote the section entitled "Nontraditional roles of vitamin D." All authors contributed to the review and revision of the entire manuscript, and all authors approved the final version submitted for publication.

Acknowledgements: The other members of the Vitamin D Working Group of Osteoporosis Canada, who made important contributions to this document, were Drs. David E. C. Cole, Stephanie A. Atkinson, Robert G. Josse, 
Sidney Feldman, Gregory A. Kline and Cheryl Rosen. The document was reviewed and approved by the Guidelines Committee of the Scientific Advisory Council of Osteoporosis Canada (chaired by William D. Leslie ): Angela Cheung, Kerry Siminoski, Alexandra Papaioannou, Sophie Jamal, Anthony Hodsman and Jacques Brown. The assistance of Loretta Hillier in condensing the original version of the manuscript and collating the references was much appreciated.

Funding: Osteoporosis Canada received a grant from the Ontario Ministry of Health and Long-Term Care to develop these guidelines as a part of a larger project to develop guidelines for the investigation and management of osteoporosis.

Endorsements: Canadian Society of Clinical Chemists, Canadian Association of Nuclear Medicine, Canadian Geriatrics Society, Canadian Orthopaedic Association, Canadian Society of Endocrinology and Metabolism, Dietitians of Canada, Ontario Association of Radiologists, Society of Obstetricians and Gynaecologists of Canada, Canadian Rheumatology Association, Canadian Pharmacists Association and Ontario College of Family Physicians.

\section{REFERENCES}

1. Brown JP, Josse RG. 2002 clinical practice guidelines for the diagnosis and management of osteoporosis in Canada. CMAJ 2002;167(Suppl):S1-34.

2. Institute of Medicine. Dietary reference intakes for calcium, phosphorus, magnesium, vitamin D and fluoride. Washington (DC): National Academy Press; 1997.

3. Shea BJ, Grimshaw JM, Wells GA, et al. Development of AMSTAR: a measurement tool to assess the methodological quality of systematic reviews. $B M C \mathrm{Med}$ Res Methodol 2007;7:10.

4. Hanley DA, Cranney A, Jones G, et al. Vitamin D in adult health and disease: a review and guideline statement from osteoporosis Canada. CMAJ 2010. DOI 10.1503/cmaj.080663.

5. Holick MF. Vitamin D deficiency. N Engl J Med 2007;357:266-81.

6. Jones G. Pharmacokinetics of vitamin D toxicity. Am J Clin Nutr 2008;88:582S-6S.

7. Armas LA, Hollis BW, Heaney RP. Vitamin $\mathrm{D}_{2}$ is much less effective than vitamin $\mathrm{D}_{3}$ in humans. J Clin Endocrinol Metab 2004;89:5387-91.

8. Binkley N, Krueger D, Cowgill CS, et al. Assay variation confounds the diagnosis of hypovitaminosis D: a call for standardization. J Clin Endocrinol Metab 2004;89: 3152-7.

9. Jones G, Horst R, Carter G, et al. Contemporary diagnosis and treatment of vitamin D-related disorders. J Bone Miner Res 2007;22(Suppl 2):V11-5.

10. Lips P, Chapuy MC, Dawson-Hughes B, et al. An international comparison of serum 25-hydroxyvitamin D measurements. Osteoporos Int 1999;9:394-7.

11. Heaney RP, Davies KM, Chen TC, et al. Human serum 25-hydroxycholecalciferol response to extended oral dosing with cholecalciferol. Am J Clin Nutr 2003;77:204-10.

12. Bacon CJ, Gamble GD, Horne AM, et al. A comparison of three high dose oral vitamin $\mathrm{D}_{3}$ supplementation regimens. J Bone Miner Res 2007;22(Suppl 1):S126.

13. Gaugris S, Heaney RP, Boonen S, et al. Vitamin D inadequacy among postmenopausal women: a systematic review. QJM 2005;98:667-76.

14. Weatherall M. A meta-analysis of 25 hydroxyvitamin $D$ in older people with fracture of the proximal femur. N Z Med J 2000;113:137-40

15. Hollis BW. Circulating 25-hydroxyvitamin D levels indicative of vitamin D sufficiency: implications for establishing a new effective dietary intake recommendation for vitamin D. J Nutr 2005;135:317-22.

16. Holick MF. Sunlight and vitamin D for bone health and prevention of autoimmune diseases, cancers, and cardiovascular disease. Am J Clin Nutr 2004;80(Suppl):1678S-88S.

17. Roth DE, Martz P, Yeo R, et al. Are national vitamin D guidelines sufficient to maintain adequate blood levels in children? Can J Public Health 2005;96:443-9.

18. Rucker D, Allan JA, Fick GH, et al. Vitamin D insufficiency in a population of healthy western Canadians. CMAJ 2002;166:1517-24.

19. Vieth R, Cole DE, Hawker GA, et al. Wintertime vitamin D insufficiency is common in young Canadian women, and their vitamin D intake does not prevent it. Eur J Clin Nutr 2001:55:1091-7.

20. Freedman DM, Looker AC, Chang SC, et al. Prospective study of serum vitamin D and cancer mortality in the United States. J Natl Cancer Inst 2007;99:1594-602.

21. Bischoff-Ferrari HA, Giovannucci E, Willett WC, et al. Estimation of optimal serum concentrations of 25-hydroxyvitamin D for multiple health outcomes. Am J Clin Nutr 2006;84:18-28.

22. Hathoock JN, Shao A, Vieth R, et al. Risk assessment for vitamin D. Am J Clin Nutr 2007;85:6-18.

23. Bischoff-Ferrari HA, Dietrich T, Orav EJ, et al. Positive association between 25hydroxy vitamin D levels and bone mineral density: a population-based study of younger and older adults. Am J Med 2004;116:634-9.

24. Dawson-Hughes B, Heaney RP, Holick MF, et al. Estimates of optimal vitamin D status. Osteoporos Int 2005;16:713-6.

25. Stone K, Bauer DC, Black DM, et al. Hormonal predictors of bone loss in elderly women: a prospective study. The Study of Osteoporotic Fractures Research Group. J Bone Miner Res 1998;13:1167-74.

26. Meier C, Woitge HW, Witte K, et al. Supplementation with oral vitamin $\mathrm{D}_{3}$ and calcium during winter prevents seasonal bone loss: a randomized controlled openlabel prospective trial. J Bone Miner Res 2004;19:1221-30.

27. Jackson RD, LaCroix AZ, Gass M, et al. Calcium plus vitamin D supplementation and the risk of fractures. N Engl J Med 2006;354:669-83.

28. Dawson-Hughes B, Harris SS, Krall EA, et al. Effect of calcium and vitamin D supplementation on bone density in men and women 65 years of age or older. $N$ Engl J Med 1997;337:670-6.

29. Chapuy MC, Pamphile R, Paris E, et al. Combined calcium and vitamin $\mathrm{D}_{3}$ supplementation in elderly women: confirmation of reversal of secondary hyperparathyroidism and hip fracture risk: the Decalyos II study. Osteoporos Int 2002;13: 257-64

30. Chapuy MC, Arlot ME, Duboeuf F, et al. Vitamin $\mathrm{D}_{3}$ and calcium to prevent hip fractures in the elderly women. N Engl J Med 1992;327:1637-42.

31. Grant AM, Avenell A, Campbell MK, et al. Oral vitamin $D_{3}$ and calcium for secondary prevention of low-trauma fractures in elderly people (Randomised Evaluation of Calcium Or vitamin D, RECORD): a randomised placebo-controlled trial. Lancet 2005;365:1621-8.

32. Bischoff-Ferrari HA, Willett WC, Wong JB, et al. Fracture prevention with vitamin D supplementation: a meta-analysis of randomized controlled trials. JAMA 2005;293:2257-64.

33. Chung M, Balk EM, Brendel M, et al. Vitamin D and calcium: a systematic review of health outcomes. Evidence Report/Technology Assessment 183. AHRQ Publ. 07E015. Rockville (MD): Agency for Healthcare Research and Quality; 2009.

34. Bischoff-Ferrari HA, Dietrich T, Orav EJ, et al. Higher 25-hydroxyvitamin D concentrations are associated with better lower-extremity function in both active and inactive persons aged $\geq 60$ y. Am J Clin Nutr 2004;80:752-8.

35. Bischoff-Ferrari HA, Orav EJ, Dawson-Hughes B. Effect of cholecalciferol plus calcium on falling in ambulatory older men and women: a 3-year randomized controlled trial. Arch Intern Med 2006;166:424-30.

36. Broe KE, Chen TC, Weinberg J, et al. A higher dose of vitamin D reduces the risk of falls in nursing home residents: a randomized, multiple-dose study. J Am Geriatr Soc 2007;55:234-9.

37. Flicker L, MacInnis RJ, Stein MS, et al. Should older people in residential care receive vitamin D to prevent falls? Results of a randomized trial. J Am Geriatr Soc 2005;53:1881-8

38. Bischoff-Ferrari HA, Dawson-Hughes B, Willett WC, et al. Effect of vitamin D on falls: a meta-analysis. JAMA 2004;291:1999-2006

39. Masuda S, Jones G. Promise of vitamin D analogues in the treatment of hyperproliferative conditions. Mol Cancer Ther 2006;5:797-808.

40. Garland CF, Garland FC, Gorham ED, et al. The role of vitamin D in cancer prevention. Am J Public Health 2006;96:252-61.

41. Gorham ED, Garland CF, Garland FC, et al. Vitamin D and prevention of colorectal cancer. J Steroid Biochem Mol Biol 2005;97:179-94.

42. Grant WB, Garland CF. A critical review of studies on vitamin D in relation to colorectal cancer. Nutr Cancer 2004;48:115-23.

43. Brown SJ. The role of vitamin D in multiple sclerosis. Ann Pharmacother 2006;40:1158-61.

44. Liu PT, Stenger S, Li H, et al. Toll-like receptor triggering of a vitamin D-mediated human antimicrobial response. Science 2006;311:1770-3.

45. Mathieu C, Gysemans C, Giulietti A, et al. Vitamin D and diabetes. Diabetologia 2005; 48:1247-57.

46. Lucas R, McMichael T, Smith W, et al. Solar ultraviolet radiation: global burden of disease from solar ultraviolet radiation. Geneva (Switzerland): World Health Organization; 2006.

47. Working Group of the Australian and New Zealand Bone and Mineral Society, Endocrine Society of Australia, Osteoporosis Australia. Vitamin D and adult bone health in Australia and New Zealand: a position statement. Med J Aust 2005;182: 281-5.

48. Webb AR. Who, what, where and when - influences on cutaneous vitamin D synthesis. Prog Biophys Mol Biol 2006;92:17-25.

49. Bischoff-Ferrari HA, Kiel DP, Dawson-Hughes B, et al. Dietary calcium and serum 25-hydroxyvitamin D status in relation to BMD among U.S. adults. $J$ Bone Miner Res 2009;24:935-42.

50. Bischoff-Ferrari HA, Willett WC, Wong JB, et al. Prevention of nonvertebral fractures with oral vitamin D and dose dependency: a meta-analysis of randomized controlled trials. Arch Intern Med 2009;169:551-61.

51. Munger KL, Levin LI, Hollis BW, et al. Serum 25-hydroxyvitamin D levels and risk of multiple sclerosis. JAMA 2006;296:2832-8.

Correspondence to: Dr. David A. Hanley, University of Calgary

Health Sciences Centre, 3330 Hospital Drive NW, Calgary AB

T2N4N1; dahanley@ucalgary.ca

This article is a summary of a full review and guideline of vitamin D in adult health and disease (available online at www.cmaj.ca) prepared by a committe of authors chosen by the Guidelines Committee of the Scientific Advisory Council of Osteoporosis Canada. The guideline is an update of the vitamin D section of the complete osteoporosis clinical practice guidelines of Osteoporosis Canada, published in 2002. 